\title{
Correction to: Scandium Effect on Undercooling and Dendrite Morphology of Al-4.5 Wt Pct Cu Droplets
}

\author{
J. VALLOTON, A.-A. BOGNO, H. HENEIN, D.M. HERLACH, and D. SEDIAKO
}

https://doi.org/10.1007/s11661-020-05649-9

(c) The Minerals, Metals \& Materials Society and ASM International 2020

\section{Correction to: \\ Metallurgical and Materials Transactions A, \\ Volume 50A, December 2019 \\ https://doi.org/10.1007/s11661-019-05463-y}

IN the original article the Acknowledgments are incomplete. Following is the corrected text:

Financial support from the Natural Sciences and Engineering Research Council of Canada (NSERC) and the Holistic Innovation in Additive Manufacturing (HIAM) Network, as well as the European Space Agency
(ESA) within the frame of the NEQUISOL project is gratefully acknowledged. The authors are grateful to the Canadian Nuclear Laboratories (CNL) and the European Synchrotron Radiation Facility (ESRF) for beam time and expert support during the measurement campaigns. The assistance of Daniel Auras with morphology analysis is appreciated.

Publisher's Note Springer Nature remains neutral with regard to jurisdictional claims in published maps and institutional affiliations.

J. VALLOTON, A.-A. BOGNO, and H. HENEIN are with the Advanced Materials and Processing Laboratory, University of Alberta, Edmonton, T6G 1H9, Canada. Contact e-mail: valloton@ualberta.ca D.M. HERLACH is with the Institut für Materialphysik im Weltraum, Deutsches Zentrum für Luft-und Raumfahrt, 51170, Cologne, Germany. D. SEDIAKO is with the UBC Okanagan, Kelowna, BC, V1V 1V7, Canada.

The original article can be found online at https://doi.org/10.1007/ s11661-019-05463-y.

Article published online January 31, 2020 